\title{
Developing tsunami fragility curves based on the satellite remote sensing and the numerical modeling of the 2004 Indian Ocean tsunami in Thailand
}

\author{
A. Suppasri, S. Koshimura, and F. Imamura \\ Disaster Control Research Center, Graduate School of Engineering, Tohoku University, Japan \\ Received: 7 May 2010 - Revised: 8 December 2010 - Accepted: 10 December 2010 - Published: 20 January 2011
}

\begin{abstract}
The 2004 Indian Ocean tsunami damaged and destroyed numerous buildings and houses in Thailand. Estimation of tsunami impact to buildings from this event and evaluation of the potential risks are important but still in progress. The tsunami fragility curve is a function used to estimate the structural fragility against tsunami hazards. This study was undertaken to develop fragility curves using visual inspection of high-resolution satellite images (IKONOS) taken before and after tsunami events to classify whether the buildings were destroyed or not based on the remaining roof. Then, a tsunami inundation model is created to reconstruct the tsunami features such as inundation depth, current velocity, and hydrodynamic force of the event. It is assumed that the fragility curves are expressed as normal or lognormal distribution functions and the estimation of the median and log-standard deviation is performed using least square fitting. From the results, the developed fragility curves for different types of building materials (mixed type, reinforced concrete and wood) show consistent performance in damage probability and when compared to the existing curves for other locations.
\end{abstract}

\section{Introduction}

The 2004 Indian Ocean megathrust earthquake occurred on 26 December 2004, creating a gigantic tsunami striking coastal communities over a large area. The earthquake with a magnitude of $9.3 M_{\mathrm{w}}$ was the second largest ever recorded and caused the deadliest tsunami disaster in history.

The tsunami devastated 11 Asian and African countries; at least 282517 people lost their lives (Asian Disaster Preparedness Center, 2007). Thailand was among the most affected
Asian countries, with a total of 8212 dead and missing and of 8457 injured, according to assessments of the tsunami impact in Thailand (Asian Disaster Preparedness Center, 2007). Regarding structural damage, 4806 houses were affected, of which 3302 houses were destroyed completely and as many as 1504 were partly damaged. The maximum water level of about $15 \mathrm{~m}$ reported at Khao Lak in the Phang Nga province and of $7 \mathrm{~m}$ at Kamala and Patong Beach in Phuket gave these areas their respective distinction as the first and second worst areas of structural damage to 2508 and 1033 houses. Six months after the disaster, approximately 7000 people were still residing in temporary shelters. A damage investigation carried out through field surveys by eight universities in Thailand using new satellite imaging technology (IKONOS) from the Geo informatics and Space Technology Development Agency (GISTDA) revealed damage to housing estimated at 21 million (M) USD and, more specifically at $14 \mathrm{M}$, $3 \mathrm{M}$ and $4 \mathrm{M}$ respectively for reconstruction, repair, and replacement of household goods. Using the building damage data with tsunami numerical simulation, the fragility curve would be a proper loss estimation tool against a potential tsunami in the future.

\section{Tsunami fragility}

Koshimura et al. (2009b) proposed the term "Tsunami fragility" as a new measure for estimating tsunami damage. Tsunami fragility is defined as the structural damage probability or fatality ratio with particular regard to the hydrodynamic features of tsunami inundation flow, such as inundation depth, current velocity, and hydrodynamic force. Koshimura et al. (2009b) described three methods to develop tsunami fragility for structural damage, as described below. 


\subsection{Tsunami fragility determined from satellite remote sensing and numerical modeling}

Koshimura et al. (2007, 2009c) developed tsunami fragility curves from a numerical method. High-resolution satellite imagery in Banda Aceh, Indonesia was used for damage detection with visual interpretation. Actually, as a limitation of this method, damage levels are classifiable at only two levels: as damaged (washed away or collapsed) and non-damaged buildings. A numerical model of tsunami propagation and coastal inundation with highresolution bathymetry/topography data was produced to determine the hydrodynamic features of tsunami inundation on land. The model results and interpretation of damaged buildings are then combined to define the relationship between the hydrodynamic features of tsunamis such as inundation depth, flow velocity, hydrodynamic force, and damage probabilities. The damage probability increases rapidly when the local inundation depth exceeds $2 \mathrm{~m}$; almost all buildings are destroyed when confronting a $4 \mathrm{~m}$ tsunami. Most buildings collapse when the current velocity exceeds $3 \mathrm{~m} \mathrm{~s}^{-1}$ and the hydrodynamic force becomes greater than $10 \mathrm{kN} \mathrm{m}^{-1}$.

Further research was carried out for the 1993 Hokkaido Nansei-oki tsunami (Okushiri tsunami) by Koshimura et al. (2009a). All 769 inspected houses and structures with damage separated into five classes were examined by using a set of pre- and post-event aerial photographs. Building damage characteristics could be expressed in terms of the developed tsunami fragility because most buildings collapsed when the inundation depth was greater than $2 \mathrm{~m}$, the current velocity was greater than $5 \mathrm{~m} \mathrm{~s}^{-1}$, and hydrodynamic forces were greater than $20 \mathrm{kN} \mathrm{m}^{-1}$. The results also satisfied Matsutomi's criteria (Matsutomi and Harada, 2010) for structural destruction of a wooden house, which provide a judgment for the degree of damage to a building (partially damaged or destroyed) to weigh against the tsunami features (inundation depth, current velocity and hydrodynamic force).

\subsection{Tsunami fragility determined from satellite remote sensing and field surveys}

Fragility curves of reinforced-concrete buildings damaged by a tsunami were established in six provinces in southern Thailand. Based on investigation results and damage levels, Foytong (2007) and Ruangrassamee et al. (2006) used their survey database of about 120 buildings in tsunami-affected provinces in Thailand to construct fragility curves. Damage levels are defined in terms of the overall damage of buildings. The four damage levels are those of no damage, damage in secondary members (roof and wall only) only, damage in primary members (beam, column and footing), and collapse. Fragility curves in their study are categorized by the number of stories in the building: buildings higher than one story, according to their assumption, are usually constructed with better quality and higher capacity than one-story buildings.
Therefore, established fragility curves can evaluate the effect of the number of stories to the building's capacity and construction quality. Their conclusions showed that the fragility curves are dependent on building capacity related to numbers of stories.

Tsunami fragility is also expressed by building damage levels from numerous field surveys conducted by Matsutomi and Harada (2010). The damage levels are categorized in three types ("certain", "moderate", and "severe") damage for different building materials such as wood, stone/brick/concrete block or reinforced concrete. As regards damage expectation against tsunami inundation depth, it is roughly inferred that severe building damage would occur at $8 \mathrm{~m}$ for reinforced concrete, $7 \mathrm{~m}$ for concrete block, and at $2 \mathrm{~m}$ for wood. Moderate building damage would occur from $3 \mathrm{~m}$ for concrete block, and from $1.5 \mathrm{~m}$ for wood.

\subsection{Tsunami fragility determined from historical data}

Historical data on damaged buildings in Japan were used and tsunami fragility curves were developed by Koshimura et al. (2009b). Their database inlcuded post-tsunami surveys, documents and reports which include both tsunami height and inundation depths for the 1896 Meiji-Sanriku, 1933 Showa-Sanriku, and 1960 Chile tsunamis. Structural damage to houses was originally classified into four categories: washed away, completely destroyed, moderately damaged, and only flooded. They concluded from their results that in the case of a $2 \mathrm{~m}$ tsunami there is less than $30 \%$ probability that a house would be destroyed and that at least $30 \%$ structural damage would result from a tsunami of 2.1-7.4 m height based on the historical data on the Sanriku tsunami (Koshimura et al., 2009b).

\subsection{Tsunami fragility for Thailand}

Tsunami fragility determined by satellite remote sensing and field surveys by Foytong and Ruangrassamee (2007) is more conveniently and reliably obtained than the by using tsunami numerical simulations, because real surveyed building data were used. However, this method might be unable to indicate fragility curves for the whole area because of the limited number of sampled buildings. In contrast, the method developed by Koshimura et al. (2009c) is apparently more complicated and time-consuming because it needs numerical simulation in a very fine grid and is based on visual interpretation of thousands or tens of thousands of buildings requiring great effort. Nevertheless, this method represents the fragility function of the whole area using all buildings located in the specific area considered against the hydrodynamic features of the tsunami. 

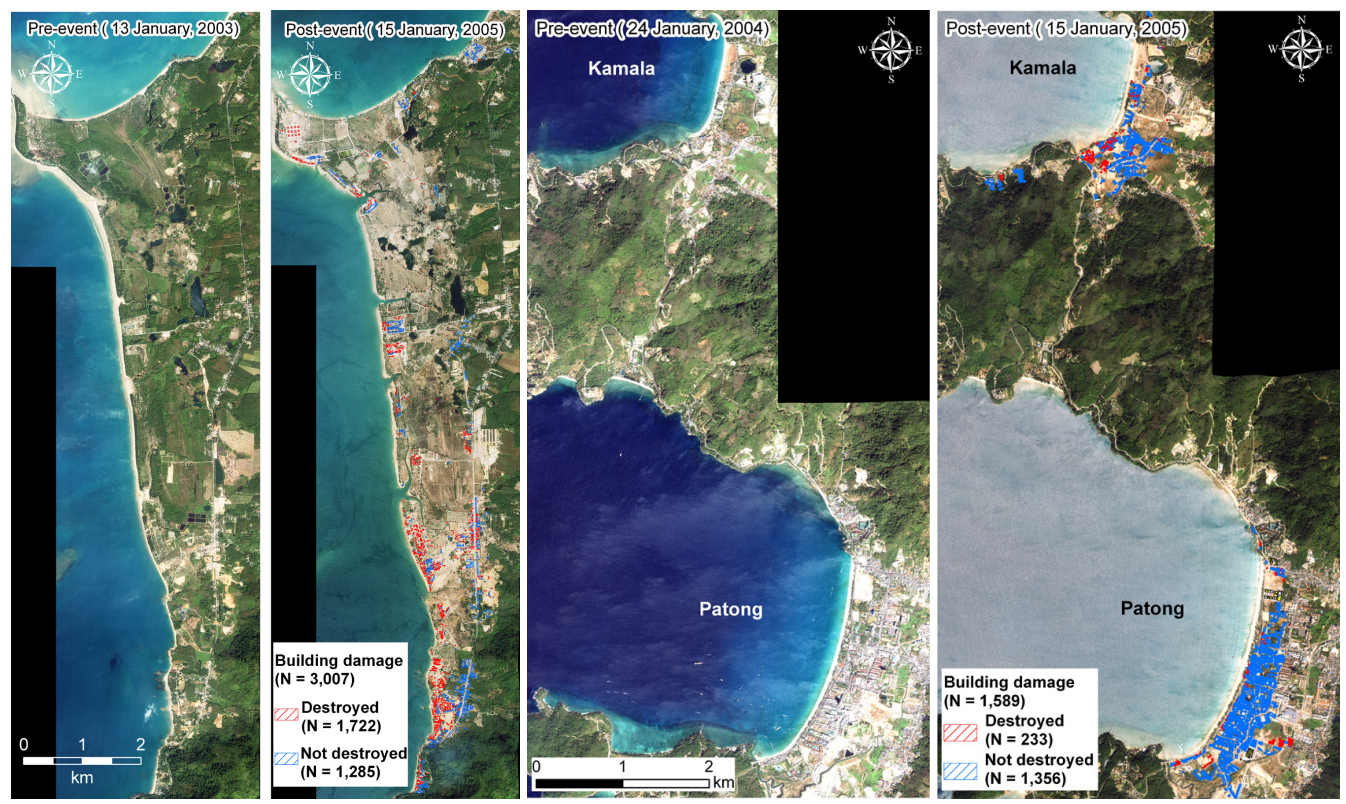

Fig. 1. Satellite images taken before and after the tsunami event and building damage in residential areas in Khao Lak, Phang Nga province and Kamala/Patong, Phuket province.

\section{Building damage in Thailand and damage inspection using satellite images}

Table 1 shows information provided by the website of the Department of Disaster Prevention and Mitigation (DDPM), Ministry of Interior, Thailand (2007) related to housing damage caused by the 2004 Indian Ocean tsunami. According to their report for housing damage in six provinces, 3302 houses were totally damaged and 1504 were partially damaged. In Phang Nga, reported figures were 1904 and 604 for totally damaged and partially damaged houses, but 742 and 291 for this in Phuket. The investigation of reinforced concrete building damage was carried out in six affected provinces along the western coast of southern Thailand by a team led by Ruangrassamee et al. (2006). Their database provides information on the building location, inundation height measured from the ground floor, structural type, column and beam damage, and the overall damage of a structure. Details of the damage levels proposed in their study were explained in Sect. 2.2.

High-resolution satellite images (IKONOS) taken before and after the tsunami event were used for visual damage interpretation. The pre-event images were acquired on 13 January 2003 and 24 January 2004 for Phang Nga and Phuket; the post-event images were both acquired on 15 January 2005 (Fig. 1). In a recent study (i.e. Gokon et al., 2010), four damage levels were classified as "not collapsed" (moderate, slight or no damage), "major damage", "collapsed" and "washed away" using the QuickBird satellite image of a $0.6 \times 0.6 \mathrm{~m}^{2}$ resolution. However, the resolution of a $1.0 \times 1.0 \mathrm{~m}^{2}$ of the IKONOS satellite image is not fine enough for a visual in-
Table 1. Housing damage reported by DDPM.

\begin{tabular}{|c|c|c|c|}
\hline \multirow{2}{*}{ Area } & \multicolumn{2}{|c|}{ House } & \multirow{2}{*}{$\begin{array}{l}\text { Total } \\
\text { (House) }\end{array}$} \\
\hline & Totally damaged & Partially damaged & \\
\hline Phang Nga & 1904 & 604 & 2508 \\
\hline Krabi & 396 & 262 & 658 \\
\hline Phuket & 742 & 291 & 1033 \\
\hline Ranong & 224 & 111 & 335 \\
\hline Trang & 34 & 156 & 190 \\
\hline Satul & 2 & 80 & 82 \\
\hline Total & 3302 & 1504 & 4806 \\
\hline
\end{tabular}

terpretation to differentiate the damage levels of buildings. Therefore, the classification of the building damage in this study was limited to "not destroyed" and "destroyed" buildings (i.e. Koshimura et al., 2009c). The remaining roof buildings were interpreted as "not destroyed" and the ones that had disappeared were "destroyed". Note that the buildings classified as "not destroyed" maybe have some sort of "damage" that cannot be identified by satellite images. Results of the building damage inspection in residential areas are presented in Fig. 1 showing damaged buildings in residential areas in Khao Lak, Phang Nga province and the populated residential area in Kamala and Patong, Phuket province. Visual interpretation data resulted in an accuracy of more than 90 percent after being checked with investigation data above. Example of destroyed buildings (red circled) and not destroyed building (blue circled) inferred from visual interpretation are 

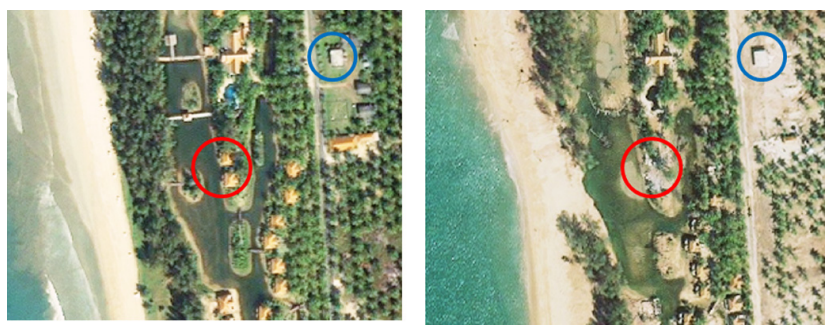

Fig. 2. Satellite images taken before and after the tsunami.
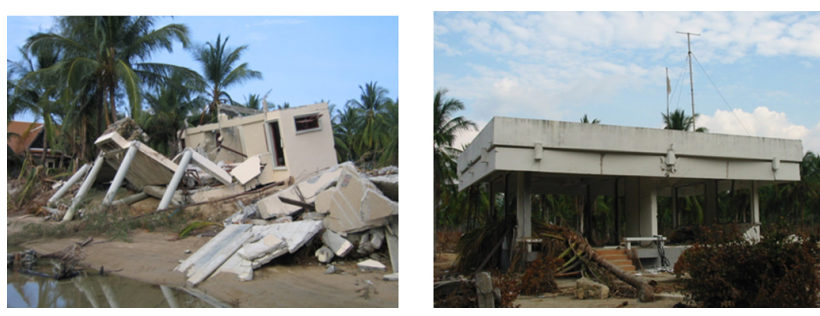

Fig. 3. Photographs of destroyed and not destroyed buildings.

depicted in Fig. 2 and are confirmed by survey data and photographs in Fig. 3. The numbers of not destroyed and destroyed buildings in the study areas are presented in Table 2. For development of tsunami fragility curves, selected buildings exclude high-rise buildings and hotels because of their apparently high structural strength.

\section{Tsunami numerical model}

\subsection{Tsunami source model}

Performances of eight proposed tsunami source models for the 2004 Indian Ocean tsunami were compared by Suppasri et al. (2008). They concluded that, especially for the water level and waveform, the model developed by the Disaster Control Research Center (DCRC) as proposed in the study of Koshimura et al. (2009c) (Fig. 4) with some modification is the best model to reproduce tsunami characteristics for tsunami studies related to Thailand. The DCRC tsunami source model itself was validated using Jason-1 altimetry data for the southern three sub-faults (faults 1-3). The vertical displacement field was revealed by satellite radar imagery and field measurement for the entire displacement field (faults 1-6). Earthquake-related fault parameters of the DCRC model are shown in Table 3 and Fig. 4. The vertical sea surface displacement field (considered to be the initial condition of tsunami) of each sub-fault's rupture with unit dislocation was calculated using the theory presented by Okada (1985).
Table 2. Details of damaged buildings in the study areas inspected from satellite images.

\begin{tabular}{lccc}
\hline Location & Not destroyed & Desrtroyed & Total \\
\hline Phang Nga (Khao Lak) & 1285 & 1722 & 3007 \\
Phuket (Patong, Kamala) & 1356 & 233 & 1589 \\
\hline
\end{tabular}

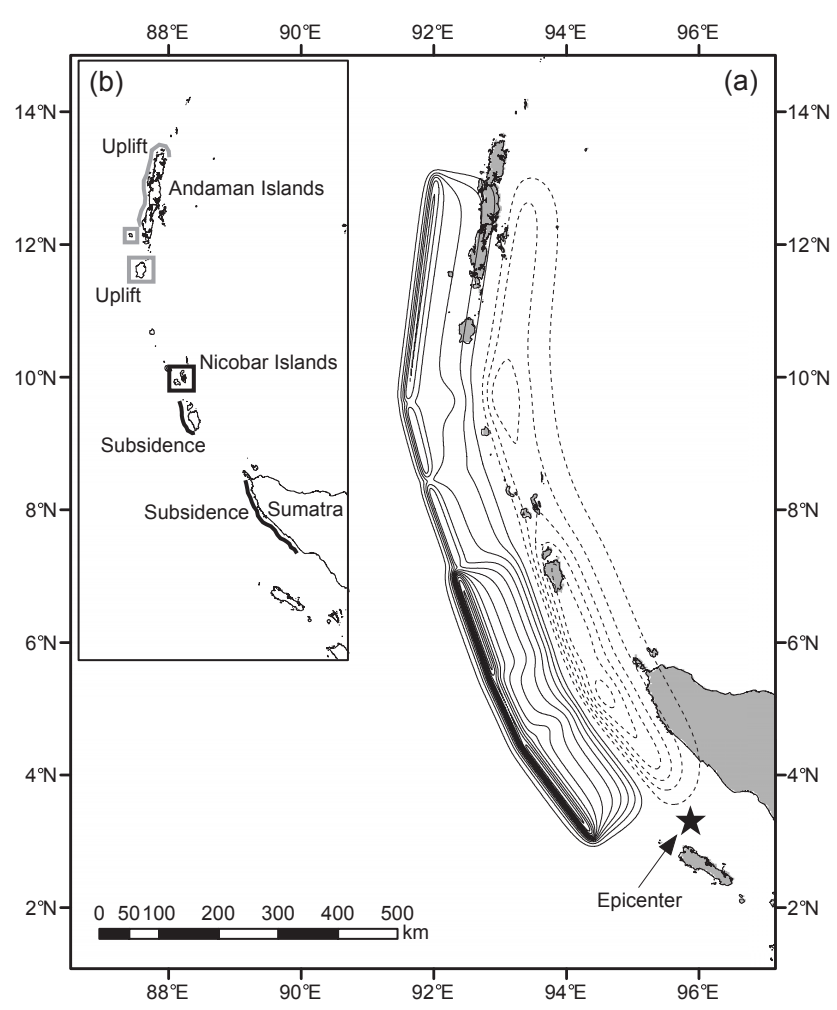

Fig. 4. Tsunami source model of the 2004 Indian Ocean tsunami (Koshimura et al., 2009c).

\subsection{Tsunami inundation model}

The tsunami inundation model was run in the two study areas in Khao Lak (Phang Nga province), and Kamala/Patong Beach (Phuket province). The set of nonlinear shallow water Eqs. (1)-(3) is discretized using a staggered leap-frog finite difference scheme (Imamura, 1995) with bottom friction in the form of Manning's formula according to a land use condition.

$$
\begin{aligned}
& \frac{\partial \eta}{\partial t}+\frac{\partial M}{\partial x}+\frac{\partial N}{\partial y}=0 \\
& \frac{\partial M}{\partial t}+\frac{\partial}{\partial x}\left(\frac{M^{2}}{D}\right)+\frac{\partial}{\partial y}\left(\frac{M N}{D}\right) \\
& =-g D \frac{\partial \eta}{\partial x}-\frac{g n^{2}}{D^{7 / 3}} M \sqrt{M^{2}+N^{2}}
\end{aligned}
$$


Table 3. Fault parameter for the 2004 Indian Ocean tsunami. The location of each fault is shown using a bottom-left position.

\begin{tabular}{lcccccc}
\hline \multirow{2}{*}{ Fault parameter } & \multicolumn{7}{c}{ Segment no. } \\
\cline { 2 - 7 } & 1 & 2 & 3 & 4 & 5 & 6 \\
\hline Latitude $\left({ }^{\circ} \mathrm{N}\right)$ & 3.03 & 4.48 & 5.51 & 7.14 & 8.47 & 9.63 \\
Longitude $\left({ }^{\circ} \mathrm{E}\right)$ & 94.40 & 93.32 & 92.87 & 92.34 & 91.88 & 91.57 \\
Strike $(\mathrm{deg})$ & 323 & 335 & 340 & 340 & 345 & 7 \\
Dip $(\mathrm{deg})$ & 15 & 15 & 15 & 15 & 15 & 15 \\
Slip $(\mathrm{deg})$ & 90 & 90 & 90 & 90 & 90 & 90 \\
Length $(\mathrm{km})$ & 200 & 125 & 180 & 145 & 125 & 380 \\
Width $(\mathrm{km})$ & 150 & 150 & 150 & 150 & 150 & 150 \\
Dislocation $(\mathrm{m})$ & 14 & 12.6 & $15.1^{*}$ & 7 & 7 & 7 \\
Depth $(\mathrm{km})$ & 10 & 10 & 10 & 10 & 10 & 10 \\
\hline
\end{tabular}

* The study revealed that the use of dislocation in segment 3 of $12 \mathrm{~m}$ for tsunami modeling in Phang Nga and $10 \mathrm{~m}$ in Phuket yields better results.
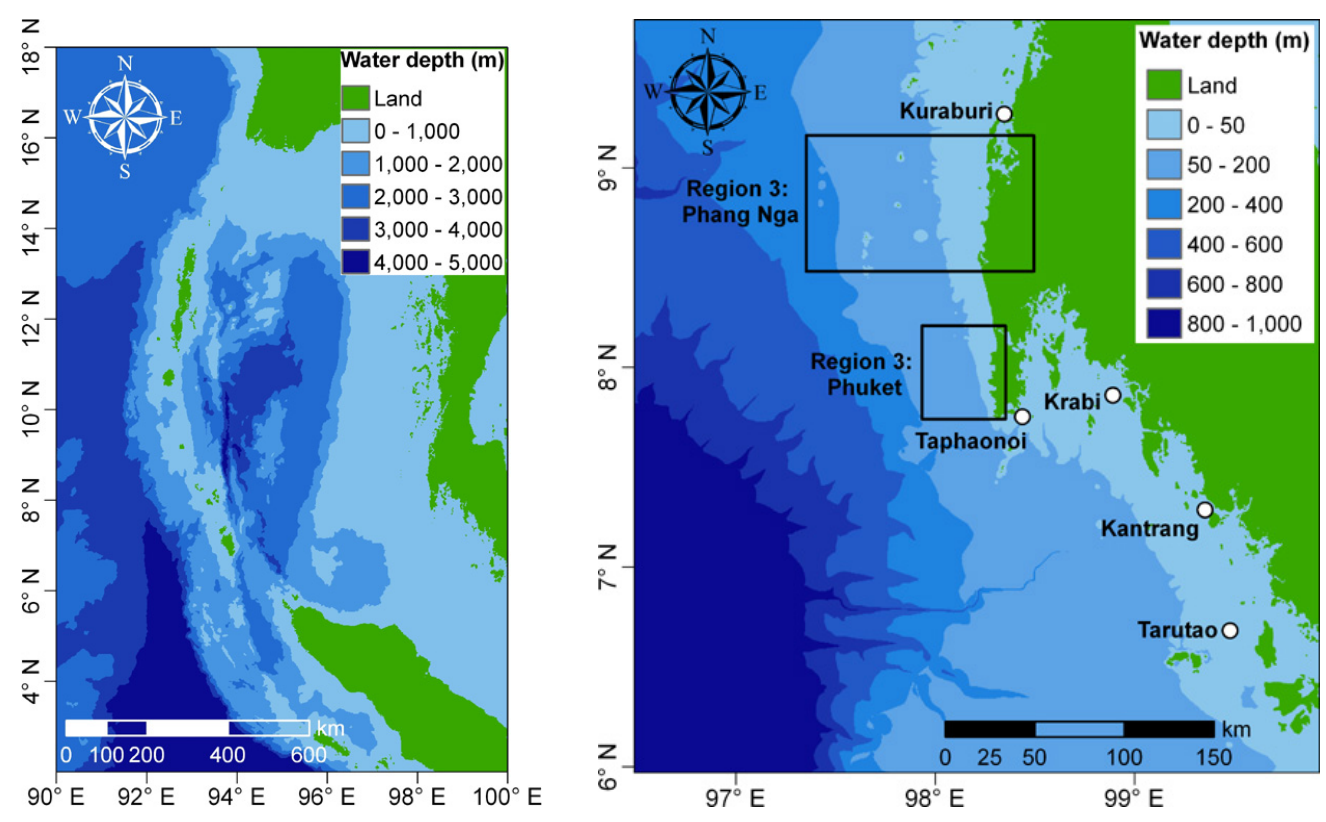

Fig. 5a. Computational areas: regions 1 and 2 .

$$
\begin{aligned}
\frac{\partial N}{\partial t} & +\frac{\partial}{\partial x}\left(\frac{M N}{D}\right)+\frac{\partial}{\partial y}\left(\frac{N^{2}}{D}\right) \\
& =-g D \frac{\partial \eta}{\partial y}-\frac{g n^{2}}{D^{7 / 3}} N \sqrt{M^{2}+N^{2}}
\end{aligned}
$$

Therein, the following definitions are used:

$$
\begin{aligned}
& M=\int_{-h}^{\eta} u d z \\
& N=\int_{-h}^{\eta} v d z \\
& D=\eta+h
\end{aligned}
$$

In these equations, $M$ and $N$ are the discharge flux of $\mathrm{x}$ - and $\mathrm{y}$-directions, respectively; $\eta$ is the water level, and $h$ is the water depth with respect to the mean sea level. Four computational domains used in a nesting grid system are depicted in Fig. 5. The largest grid size of $1855 \mathrm{~m}$ (Fig. 5a, left) is obtained from the General Bathymetric Chart of the Oceans (GEBCO), whereas $465 \mathrm{~m}$ (Fig. 5a, right), $155 \mathrm{~m}$ (Fig. 5b), and $52 \mathrm{~m}$ (Figs. 6 and 7) are obtained by the digitized navigation charts and digital data from the Royal Thai Survey Department and the Royal Thai Navy (Foytong, 2007).

\subsection{Resistance law within a tsunami inundation zone}

In general, two methods exist for modeling flow resistance depending on the relation between the scale of an obstacle and the grid size. They are the topography model and the equivalent roughness model (Hong, 2004). The topography 

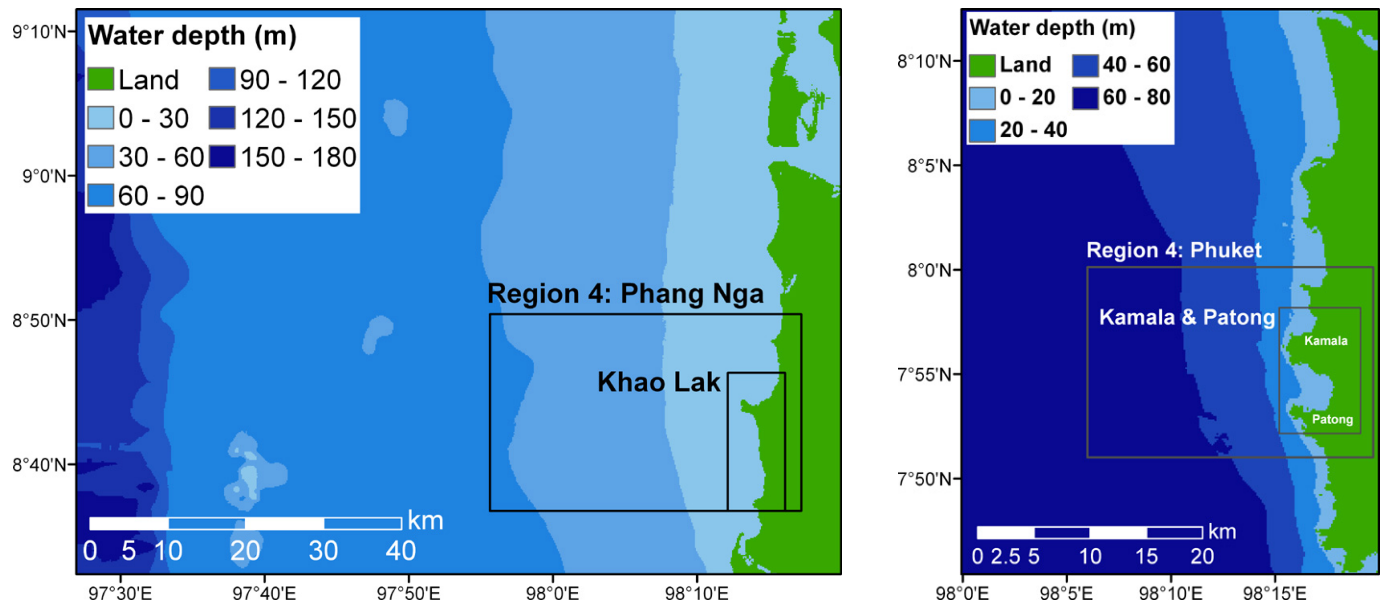

Fig. 5b. Computational areas: region 3 in Phang Nga and Phuket.

Table 4. Manning's roughness coefficient, $n$.

\begin{tabular}{lc} 
Smooth ground & 0.020 \\
Shallow water area or Natural beach & 0.025 \\
Vegetated area & 0.030 \\
Densely populated area & Eq. (7) \\
\hline
\end{tabular}

model is used when the grid size is finer than the obstacle. The tsunami in the model simulation will not pass into a grid space that is occupied by an obstacle. Then the flow around an obstacle and the contracting flow between obstacles can be simulated. However, in a larger grid size such as that of this study, the obstacle is smaller than the grid size. The equivalent roughness model is then appropriate for this problem. The equivalent roughness with appropriate consideration of the hydraulic characteristics is introduced by Aburaya and Imamura (2002). Hong (2004) also clarified his calculation results of the equivalent roughness model with a grid size of $13.7 \mathrm{~m}$ at an occupation ratio of $43 \%$ when applying it to the 1983 tsunami that affected the eastern Korean coast.

\subsubsection{Flow resistance in a non-residential area}

The equivalent roughness model is applied in the region 4, the finest region of $52 \times 52 \mathrm{~m}^{2}$ resolution, as described in Sect. 4.2. The roughness coefficient is inferred from land use throughout the study area. Figures 6 (left) and 7 (left) show the roughness coefficient distribution adopted from the land use map in the study area during the period 20002002 provided by the Land Development Department (2009). It is used to quantify the Manning's roughness coefficient $\left(\mathrm{s} \mathrm{m}^{-1 / 3}\right)$ as shown in Table 4 . The lowest Manning's roughness coefficient is 0.02 for smooth ground followed by 0.025 for shallow water area or natural beach and by 0.03 for veg- etated area. However, Manning's roughness coefficient in a densely populated area is very much affected by the number of buildings in each computational grid. A method for calculating the Manning's roughness coefficient appropriate for building aggregations is explained in the following section.

\subsubsection{Flow resistance in a residential area}

Especially in a densely populated town, in which the building occupation ratio is high, the resistance law with the composite equivalent roughness coefficient according to land use and building conditions was first studied by Aburaya and Imamura (2002) and was recently applied by Koshimura et al. (2009c), as shown in Eq. (7).

$n=\sqrt{n_{0}^{2}+\frac{C_{\mathrm{D}}}{2 g d} \times \frac{\theta}{100-\theta} \times D^{4 / 3}}$

In this equation, $n_{0}$ signifies the Manning's roughness coefficient $\left(n_{0}=0.025, \mathrm{~s} \mathrm{~m}^{-1 / 3}\right), \theta$ denotes the building/house occupation ratio in percentages ranging from 0 to 100 in the finest computational grid of $52 \mathrm{~m}$ and obtained by calculating the building area over grid area using GIS data. $C_{\mathrm{D}}$ represents the drag coefficient $\left(C_{\mathrm{D}}=1.5\right.$, e.g. FEMA (Federal Emergency Management Agency), 2003), $d$ stands for the horizontal scale of houses ( $15 \mathrm{~m}$ in average is used), and $D$ is the modeled flow depth. The occupation ratios for respective areas are shown in Figs. 6 (right) and 7 (right). The average occupation ratios in residential areas for Phang Nga and Phuket are, respectively about $25 \%$ and $40 \%$.

\subsection{Tsunami inundation model results and validation}

\subsubsection{Validation of the tsunami source model and waveform}

Tsunami waveforms in five tidal gauge stations surrounding Thailand (Fig. 5a right) were modeled and compared to 

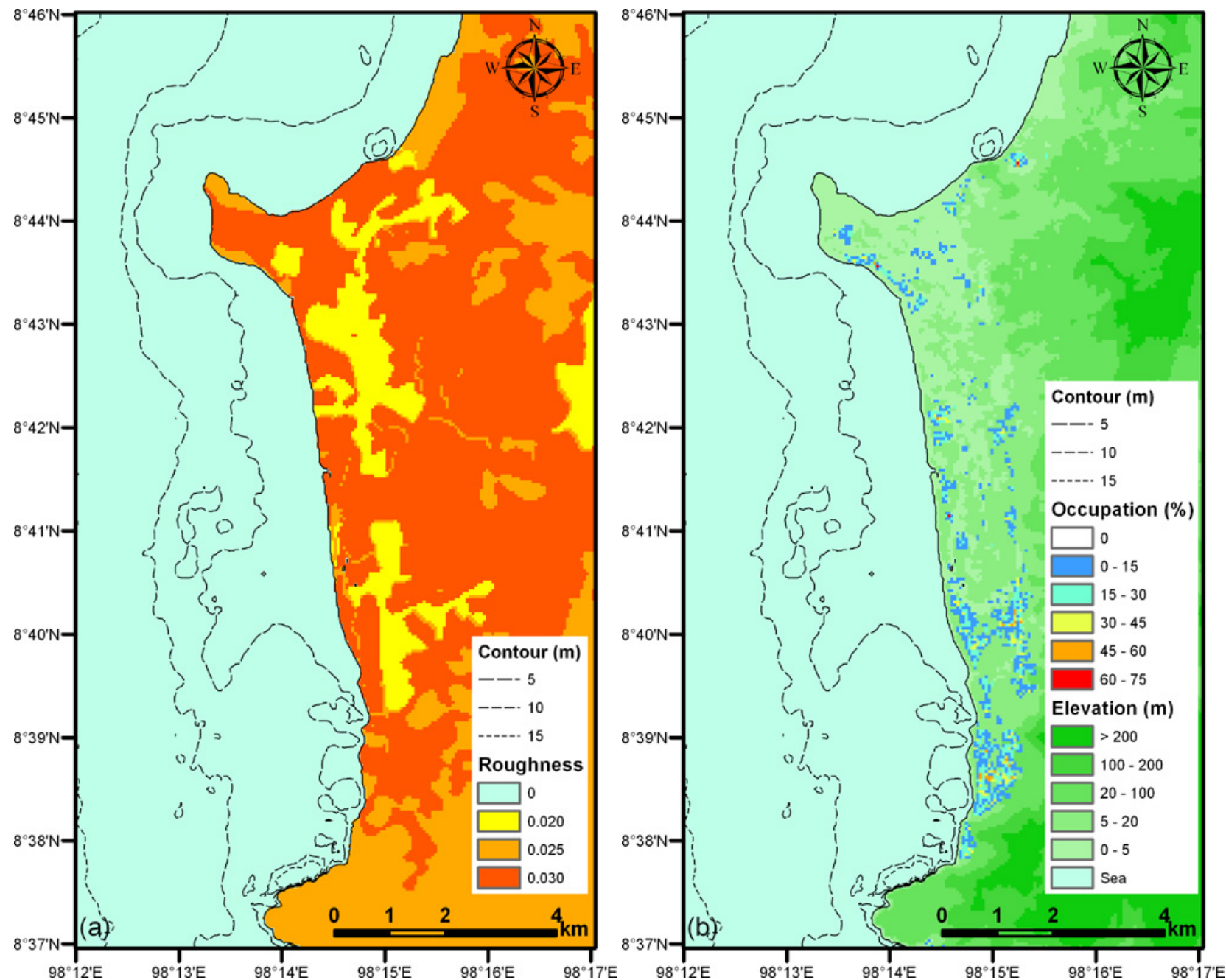

Fig. 6. Computational areas: region 4 in Khao Lak, Phang Nga including the roughness coefficient and the building occupation ratio.

recorded data. The bathymetric effect is illustrated by comparing waveforms obtained in region 1 (R1) and region 2 (R2) as shown in Fig. 8. Improvement of simulated waveforms can be seen for both the water level and arrival time in all locations, especially in Kuraburi, Taphaonoi, and Krabi. With the difference in grid size of four times $(1855 \mathrm{~m}$ to $465 \mathrm{~m}$ ), finer bathymetry in the region 2 is more detailed and accurate. Consequently, the authors recommend the use of detailed bathymetry since it can help increase the accuracy of the waveform output.

Validation of the computed waveforms is performed using the Root Mean Square Error (RMSE), and the parameters $K$ and $\kappa$ proposed by Aida (1978), as defined below:

$\log K=\frac{1}{n} \sum_{i=1}^{n} \log K_{i}$

$\log \kappa=\sqrt{\frac{1}{n} \sum_{i=1}^{n}\left(\log K_{i}\right)^{2}-(\log K)^{2}}$
$K_{i}=\frac{x_{i}}{y_{i}}$

Therein, $x_{i}$ and $y_{i}$ are the recorded and computed amplitudes of waveforms at station $i$. Thus, $K$ is defined as the geometrical mean of $K_{i}$ and $\kappa$ is defined as deviation or variance from $K$. These indices are used as criteria to validate the model through the comparison between the modeled and measured tsunamis.

The location and detail of each station are shown in Table $5 \mathrm{a}$, including the wave amplitude and Table $5 \mathrm{~b}$ for the wave arrival time. The model results show good overall performance at most stations, although some stations such as Kantrang and Tarutao provide some differences in amplitude and arrival time. The values of $K$ and $\kappa$ for the first wave trough and crest, as shown in Table 6, prove the excellence of the tsunami source model and the modeled waveform.

The fault rupture velocity of the 2004 tsunami varies from 0.7 to $2.8 \mathrm{~km} \mathrm{~s}^{-1}$ (Suppasri et al., 2010). However, to ascertain the tsunami propagation characteristic of the model, this 

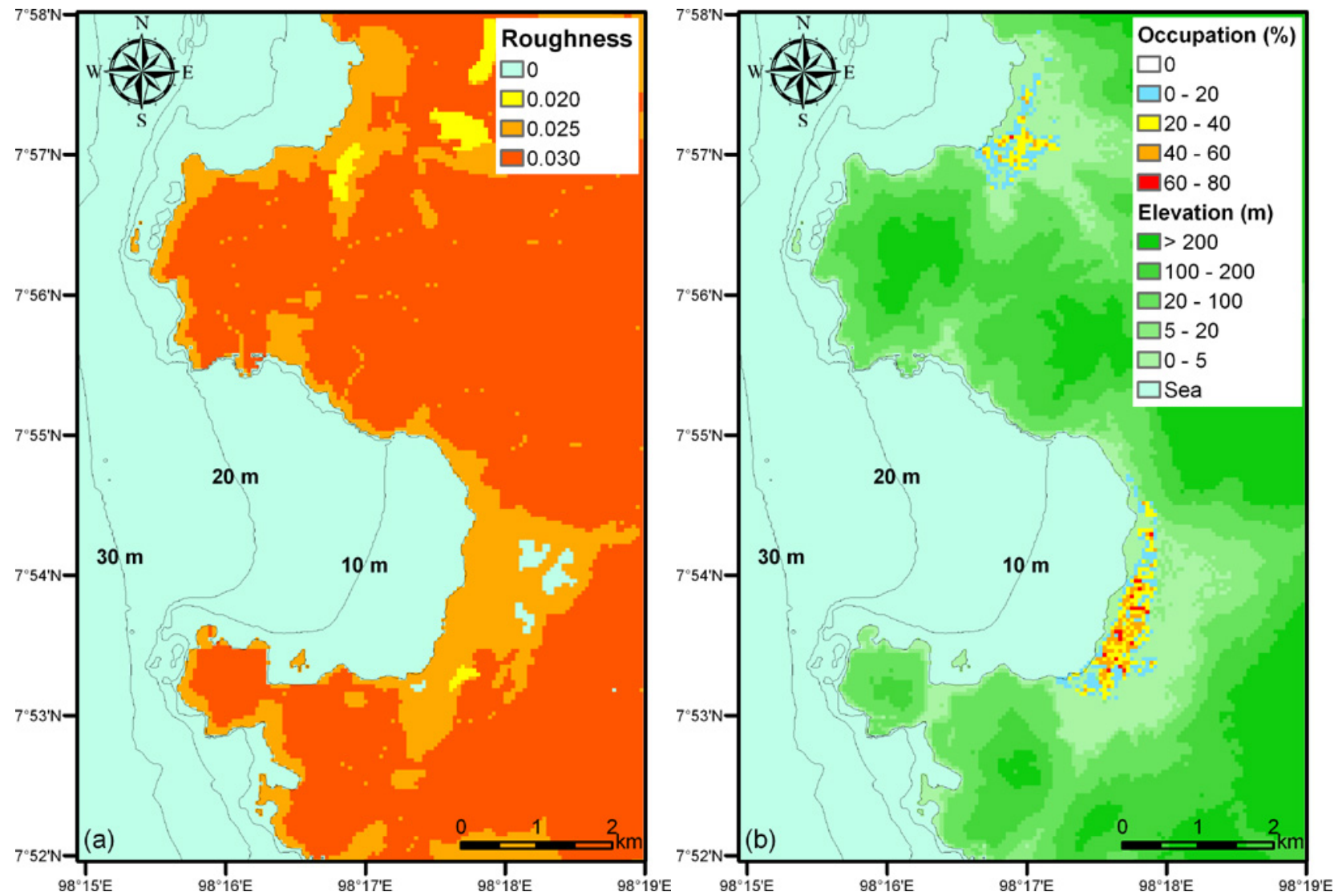

Fig. 7. Computational areas: Region 4 in Kamala/Patong, Phuket and the roughness coefficient and the building occupation ratio.

Table 5a. Detail of tide gauges for location of computing waveform and model results.

\begin{tabular}{|c|c|c|c|c|c|c|c|}
\hline \multirow{2}{*}{ Station name } & \multirow{2}{*}{ Latitude $\left({ }^{\circ} \mathrm{N}\right)$} & \multirow{2}{*}{ Longitude $\left({ }^{\circ} \mathrm{E}\right)$} & \multirow{2}{*}{$\begin{array}{c}\text { Water depth (m) } \\
\text { Region } 2\end{array}$} & \multicolumn{2}{|c|}{ Wave trough $(\mathrm{m})$} & \multicolumn{2}{|c|}{ Wave crest (m) } \\
\hline & & & & Recorded & Modeled & Recorded & Modeled \\
\hline 1. Kuraburi & 9.25 & 98.28 & 13.5 & 0.83 & 0.33 & 0.50 & 0.40 \\
\hline 2. Krabi & 8.01 & 98.90 & 1.0 & 0.66 & 0.62 & 1.29 & 0.73 \\
\hline 3. Taphaonoi & 7.76 & 98.43 & 47.4 & 1.31 & 1.56 & 0.80 & 1.36 \\
\hline 4. Kantrang & 7.26 & 99.50 & 3.7 & 0.58 & 0.43 & 0.78 & 0.65 \\
\hline 5. Tarutao & 6.72 & 99.65 & 8.2 & 0.92 & 1.40 & 1.07 & 2.60 \\
\hline
\end{tabular}

study simulated waveforms by using nonlinear equations in region 2 with a rupture velocity of 1.0 and $2.5 \mathrm{~km} \mathrm{~s}^{-1}$. The results show very small differences in amplitude $(10-20 \mathrm{~cm})$ and arrival time $(5-10 \mathrm{~min})$. It is noted here that waveforms computed using nonlinear equations in $465 \mathrm{~m}$ bathymetry and by neglecting the dynamic effect of the fault motion can produce the best waveform output after validation by the recorded data.

\subsubsection{Validation of the tsunami inundation model}

The model results are also validated using field survey data of water levels by the Kyoto University team (Research group, 2009) and inundation depths by the Chulalongkorn University team (CU-EVR, 2009) of 36 and 70 locations in the study area (Fig. 9). The water level data are based on water marks or debris on buildings above the astronomical tide level when the tsunami arrived, while the inundation depth refers to the level of the water mark on structures or debris above ground. The modeled inundation depth is presented in Figs. 10 and 11. In Phang Nga, the damage was due to a water level and 
Table 5b. Detail of tide gauges for location of computing waveform and model results.

\begin{tabular}{lccccccc}
\hline & \multicolumn{5}{c}{ Arrival time (min) } \\
\cline { 2 - 3 } \cline { 6 - 7 } \cline { 5 - 7 } \cline { 5 - 7 } & \multicolumn{3}{c}{ First wave trough } & & \multicolumn{3}{c}{ First wave crest } \\
\cline { 2 - 3 } \cline { 6 - 8 } & Recorded & Modeled & Difference* & & Recorded & Modeled & Difference* \\
\hline 1. Kuraburi & 181 & 183 & +2 & & 201 & 203 & +2 \\
2. Krabi & 200 & 194 & -6 & & 230 & 217 & -13 \\
3. Taphaonoi & 120 & 110 & -10 & & 130 & 127 & -3 \\
4. Kantrang & 258 & 217 & -41 & & 290 & 283 & -7 \\
5. Tarutao & 175 & 194 & -19 & & 180 & 207 & +27 \\
\hline
\end{tabular}

* Plus sign represents late arrival time, where minus sign stands for early arrival time
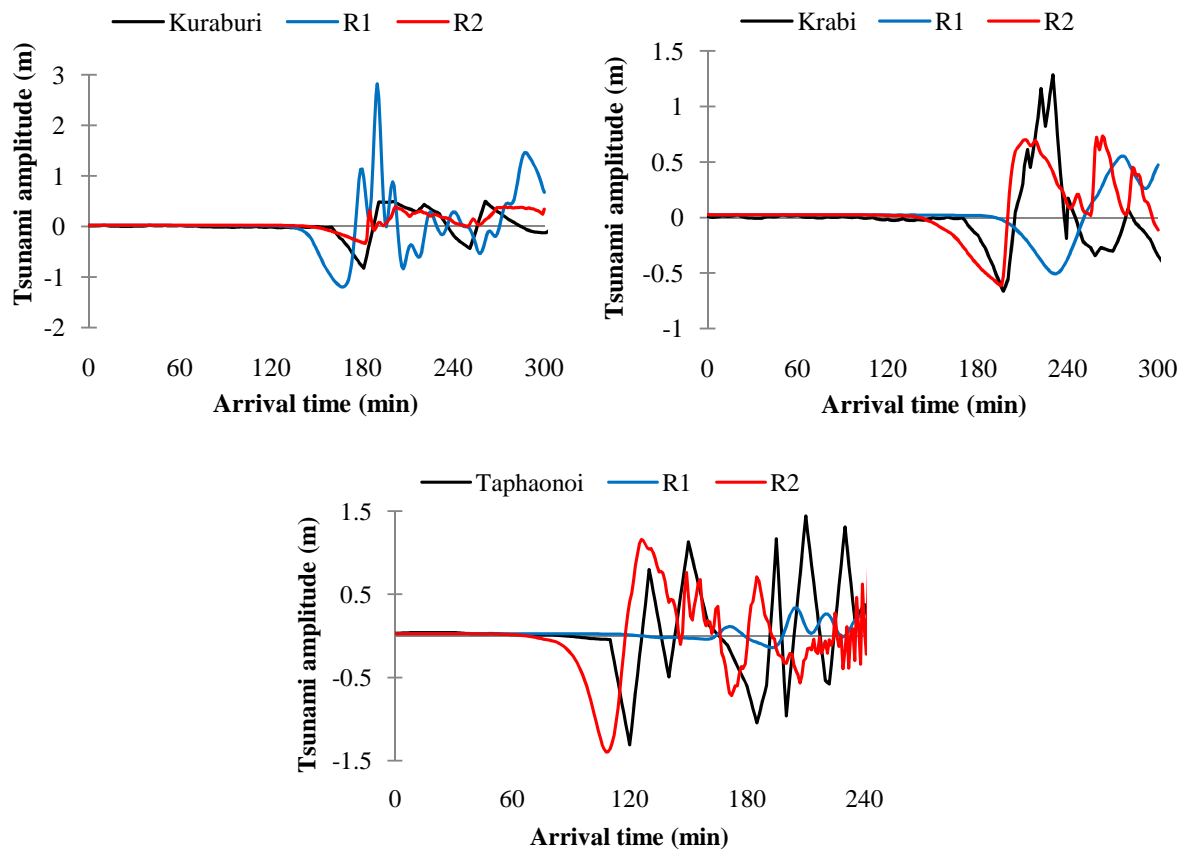

Fig. 8. Example of waveform comparison for data from tide gauge stations in Thailand.

Table 6. Validation of the modeled waveform results.

\begin{tabular}{lcccc}
\hline Model results & RMSE $(\mathrm{m})$ & $K$ & $\kappa$ & Average $\Delta t$ \\
\hline First wave trough & 0.34 & 1.15 & 1.58 & -16 \\
First wave crest & 0.77 & 0.92 & 1.71 & -10 \\
\hline
\end{tabular}

inundation depth of $10 \mathrm{~m}$ and $6 \mathrm{~m}$, respectively, which were greater than those of $5 \mathrm{~m}$ and $4 \mathrm{~m}$ in Phuket. From the results shown in Fig. 9, agreement can be found within a range of $2 \mathrm{~m}$ for the water level, but up to $1 \mathrm{~m}$ for the inundation depth. The inundation distance on land was found to be about $2 \mathrm{~km}$ in Khao Lak, Phang Nga, because of the large wave and the flat topography. On the other hand, the inundation distance
Table 7. Validation of the modeled maximum water level and inundation depth results.

\begin{tabular}{lccc}
\hline Model results & RMSE $(\mathrm{m})$ & $K$ & $\kappa$ \\
\hline Water level $(n=36)$ & 1.67 & 1.10 & 1.24 \\
Inundation depth $(n=70)$ & 0.66 & 0.84 & 1.30 \\
\hline
\end{tabular}

in Patong and Kamala beach, Phuket, was less than $1 \mathrm{~km}$ because of the smaller wave inundating through dense building population buildings.

Again, validation of the computed water levels and imnundation depths was performed using the Root Mean Square Error (RMSE), and $K$ and $\kappa$ proposed by Aida (1978), as 

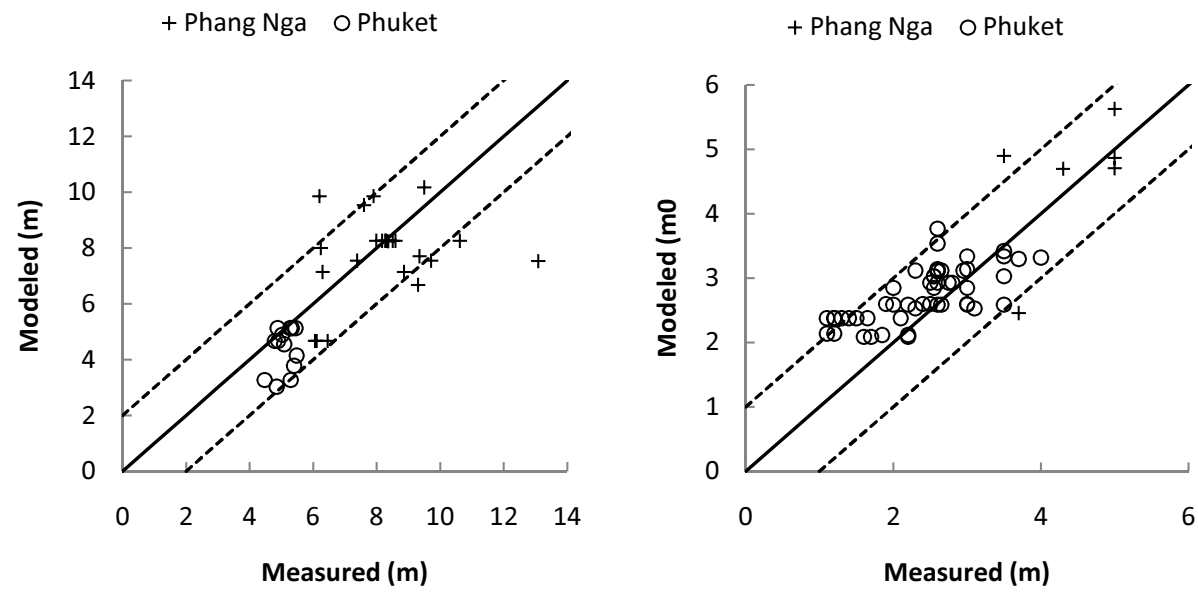

Fig. 9. Comparison of model results and measured data of the water level and inundation depths.
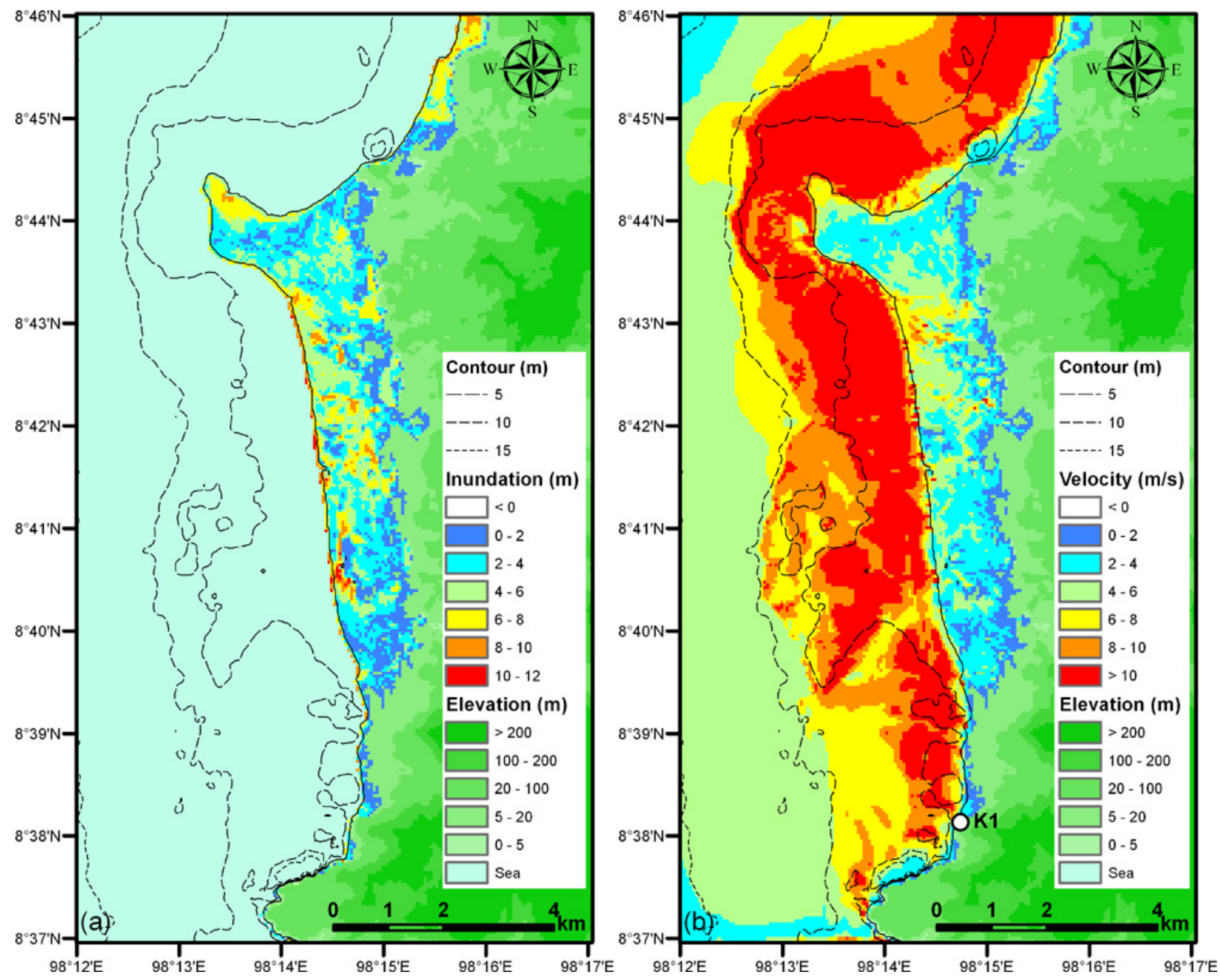

Fig. 10. Modeled inundation depth and current velocity at Khao Lak, Phang Nga. 

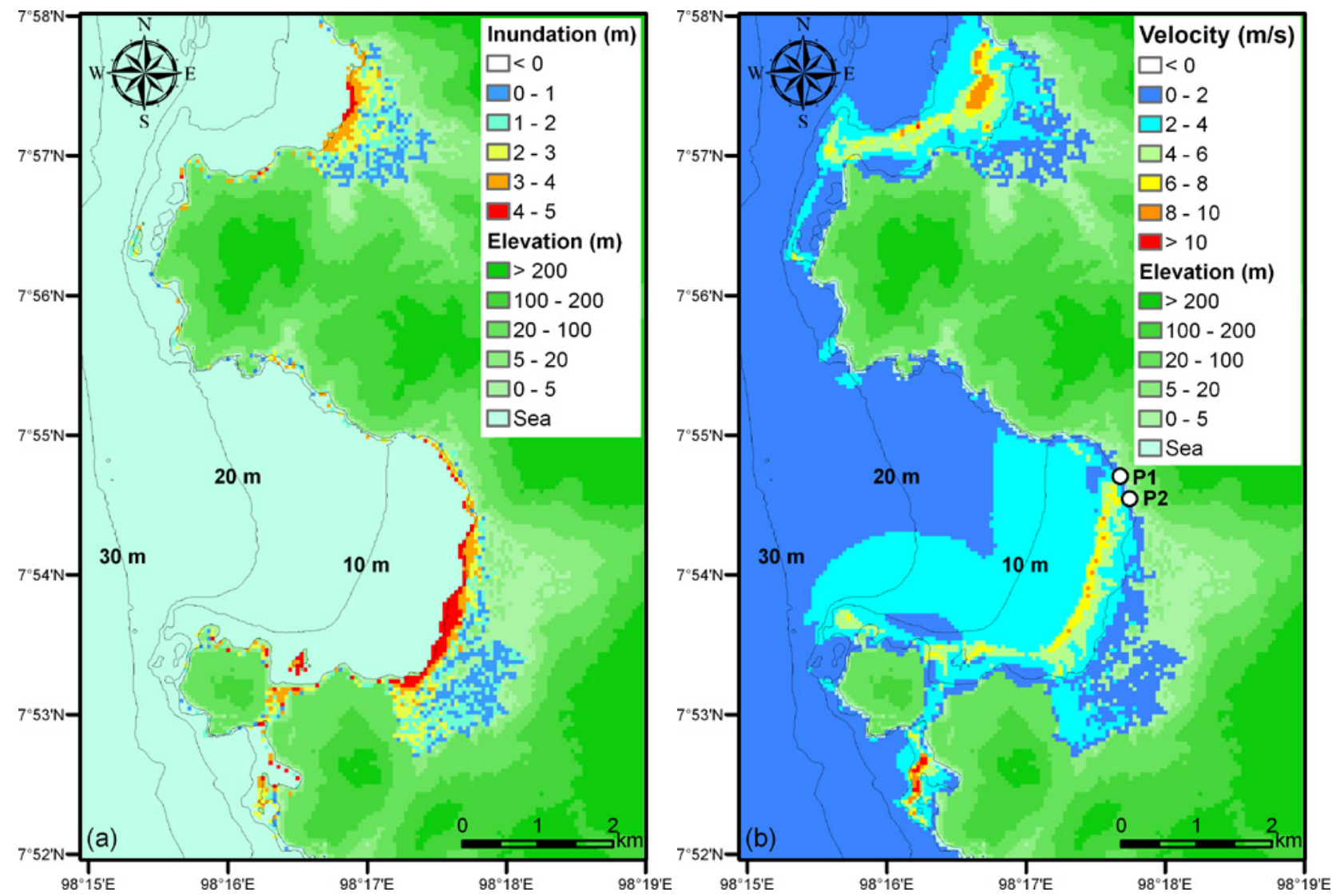

Fig. 11. Modeled inundation depth and current velocity at Kamala and Patong, Phuket.

described in Eqs. (8)-(10). However, now $K_{i}$ is defined by the following equation:

$K_{i}=\frac{R_{i}}{H_{i}}$

In this equation, $R_{i}$ and $H_{i}$ respectively denote the measured and modeled values of inundation height and inundation depth at point $i$. The $K$ and $\kappa$ for the modeled water levels $(n=36)$ and inundation depths $(n=70)$ in the computational domain are shown in Table 7. The Japan Society of Civil Engineers, JSCE (2002) provides guidelines suggesting that $0.95<K<1.05$ and $\kappa<1.45$ is recommended as "Good agreement" in the tsunami source model and propagation/inundation model evaluation. In this study, the $\kappa$ value satisfies the standard provided whereas the $K$ value is exceeding. In this sense, the simulation results cannot be considered "Good agreement". However, the results are quite improved and validated by the recorded tsunami waveforms (Fig. 8). Moreover, this is only the best simulation that can be performed under the limitation of using the available tsunami source model of the 2004 tsunami and the finest bathymetry and topography data of $52 \mathrm{~m}$.

The current velocities were obtained after tracking the survivors' videos according to a study from Foytong (2007).
The model is also validated using the maximum current velocity. The measured velocity of $8.0 \mathrm{~m} \mathrm{~s}^{-1}$ at a beachfront area in Khao Lak was validated using the modeled $8.3 \mathrm{~m} \mathrm{~s}^{-1}$ (Fig. 10, point K1). Two locations in Patong Beach of 8.9 and $7.0 \mathrm{~m} \mathrm{~s}^{-1}$ were validated respectively by modeled velocities of 6.3 and $6.1 \mathrm{~m} \mathrm{~s}^{-1}$ (Fig. 11, point P1 and P2).

\section{Developing tsunami fragility curves}

From the visual inspection of damaged buildings based on the remaining roof structures, a histogram of tsunami features (inundation depth, current velocity, and hydrodynamic force) and the number of buildings including the ones not destroyed and the ones destroyed was plotted. The damage probabilities of buildings and a discrete set were calculated and shown against a median value within a range of about 100 buildings in Phang Nga and 50 buildings in Phuket. Linear regression analysis was performed to develop the fragility function.

The cumulative probability $P$ of occurrence of damage is given either by Eqs. (12) or by (13):

$$
P(x)=\Phi\left[\frac{x-\mu}{\sigma}\right]
$$



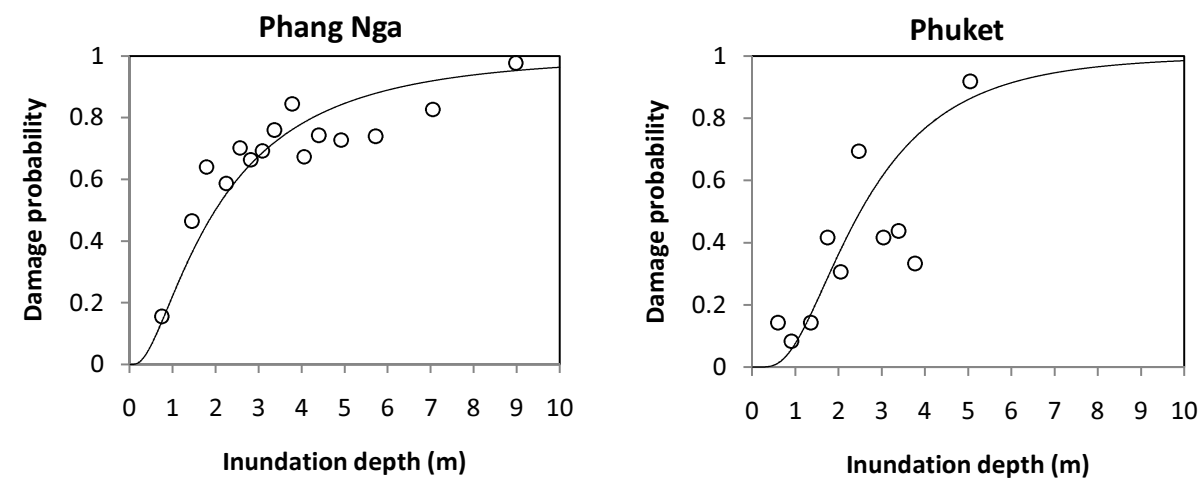

Fig. 12. Tsunami fragility curves for structural destruction as a function of the inundation depth.
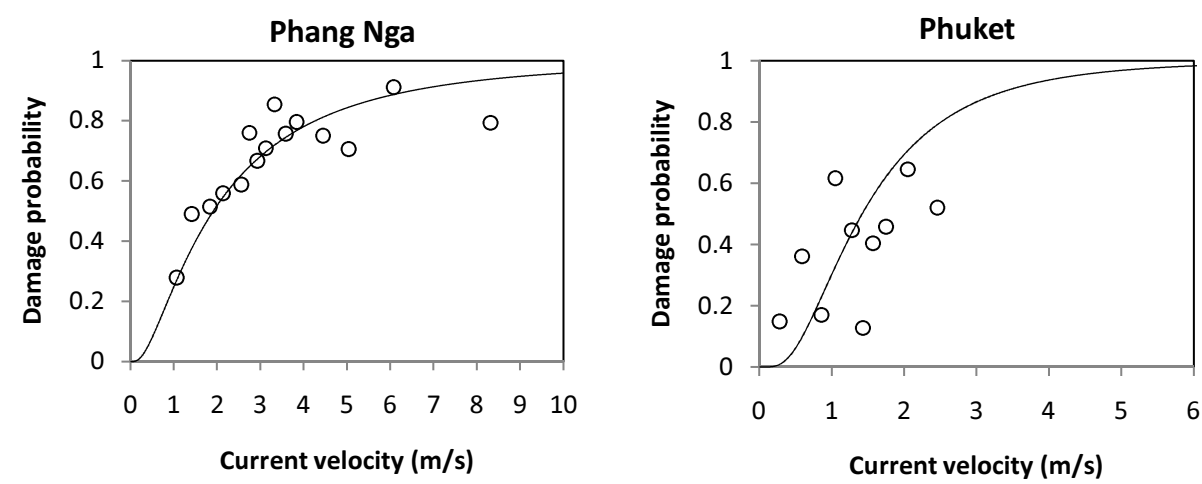

Fig. 13. Tsunami fragility curves for structural destruction as a function of the current velocity.
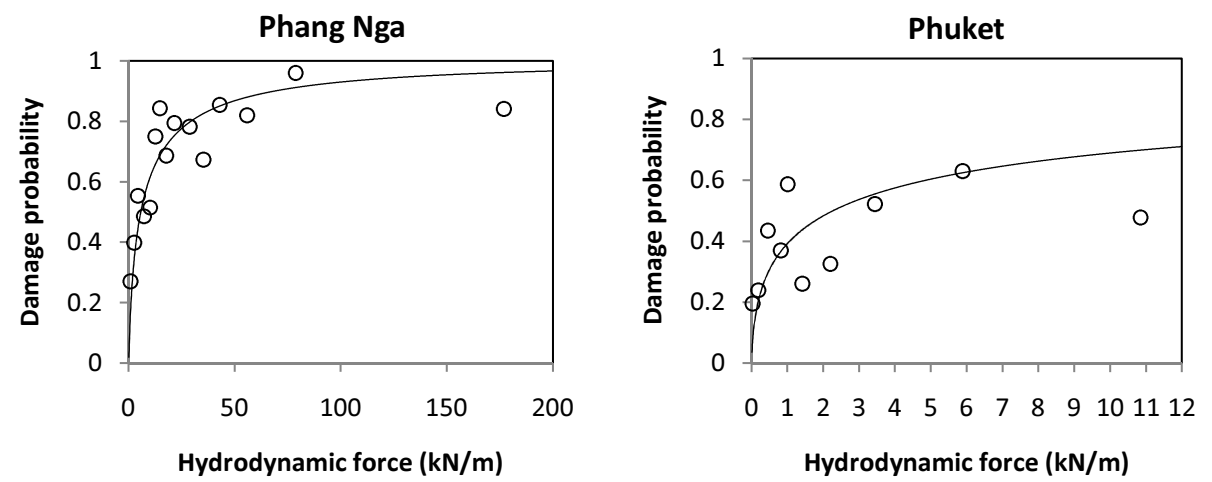

Fig. 14. Tsunami fragility curves for structural destruction as a function of the hydrodynamic force.

$P(x)=\Phi\left[\frac{\ln x-\mu^{\prime}}{\sigma^{\prime}}\right]$

In these equations, $\Phi$ represents the standardized normal (lognormal) distribution function, $x$ stands for the hydrodynamic feature of tsunami (e.g., inundation depth, current velocity and hydrodynamic force), and $\mu$ and $\sigma\left(\mu^{\prime}\right.$ and $\left.\sigma^{\prime}\right)$ respectively signify the mean and standard deviation of $x(\ln x)$. Two statistical parameters of fragility function, $\mu$ and $\sigma\left(\mu^{\prime}\right.$ and $\sigma^{\prime}$ ), are obtained by plotting $x(\ln x)$ against the inverse of $\Phi$ on normal or lognormal probability papers, and per- forming least-squares fitting of this plot. Consequently, two parameters were obtained by taking the intercept $\left(=\mu\right.$ or $\left.\mu^{\prime}\right)$ and the angular coefficient $\left(=\sigma\right.$ or $\left.\sigma^{\prime}\right)$ in Eq. (14) or (15):

$$
\begin{aligned}
& x=\sigma \Phi^{-1}+\mu \\
& \ln x=\sigma^{\prime} \Phi^{-1}+\mu^{\prime}
\end{aligned}
$$

Throughout the regression analysis, the parameters were determined as shown in Table 8 to obtain the best fit of fragility curves with respect to the inundation depth (Fig. 12), the 
Table 8. Parameters for tsunami fragility curves.

\begin{tabular}{|c|c|c|c|c|c|}
\hline \multicolumn{6}{|l|}{ Khao Lak, Phang Nga } \\
\hline$X$ for fragility function $P(x)$ & $\mu$ & $\sigma$ & $\mu^{\prime}$ & $\sigma^{\prime}$ & $R^{2}$ \\
\hline Inundation depth (m) & - & - & 0.689 & 0.903 & 0.80 \\
\hline Current velocity $\left(\mathrm{m} \mathrm{s}^{-1}\right)$ & - & - & 0.649 & 0.952 & 0.72 \\
\hline Hydrodynamic force per width $\left(\mathrm{kN} \mathrm{m}^{-1}\right)$ & - & - & 1.748 & 1.937 & 0.75 \\
\hline \multicolumn{6}{|l|}{ Kamala/Patong, Phuket } \\
\hline$X$ for fragility function $P(x)$ & $\mu$ & $\sigma$ & $\mu^{\prime}$ & $\sigma^{\prime}$ & $R^{2}$ \\
\hline Inundation depth (m) & - & - & 0.917 & 0.642 & 0.62 \\
\hline Current velocity $\left(\mathrm{m} \mathrm{s}^{-1}\right)$ & - & - & 0.352 & 0.675 & 0.32 \\
\hline Hydrodynamic force per width $\left(\mathrm{kN} \mathrm{m}^{-1}\right)$ & - & - & 0.821 & 3.000 & 0.50 \\
\hline
\end{tabular}

Table 9. Comparison of proposed and developed tsunami fragility functions.

\begin{tabular}{cccccc}
\hline $\begin{array}{c}\text { Damage probability } \\
(\%)\end{array}$ & $\begin{array}{c}\text { Banda Aceh } \\
\text { (Indonesia) }\end{array}$ & $\begin{array}{c}\text { Okushiri } \\
\text { (Japan) }\end{array}$ & $\begin{array}{c}\text { Phang Nga } \\
\text { (Thailand) }\end{array}$ & $\begin{array}{c}\text { Phuket } \\
\text { (Thailand) }\end{array}$ & $\begin{array}{c}\text { Six provinces } \\
\text { in Thailand* }\end{array}$ \\
\hline 25 & 2.25 & 1 & 1.5 & 2 & 4 \\
50 & 3 & 1.5 & 3 & 3 & 6.25 \\
75 & 4 & 2 & 4.5 & 3.75 & 10 \\
100 & 6 & 5 & 8 & 6 & $>10$ \\
\hline
\end{tabular}

* Fragility curves were developed for reinforced-concrete buildings only.

maximum current velocity (Fig. 13) and the hydrodynamic force on structures per unit width (Fig. 14). Here the hydrodynamic force acting on a structure is defined as its drag force per unit width, as

$F=\frac{1}{2} C_{\mathrm{D}} \rho u^{2} D$

where $C_{\mathrm{D}}$ denotes the drag coefficient $\left(C_{\mathrm{D}}=1.0\right.$ for simplicity), $\rho$ is the density of water $\left(=1000 \mathrm{~kg} \mathrm{~m}^{-3}\right), u$ stands for the current velocity $\left(\mathrm{m} \mathrm{s}^{-1}\right)$, and $D$ is the inundation depth (m). From this result, all fragility functions in Thailand with respect to inundation depth, current velocity and hydrodynamic force are given by the standardized lognormal distribution functions with $\mu^{\prime}$ and $\sigma^{\prime}$.

\section{Discussion and conclusions}

\subsection{Comparison between the developed and the existing tsunami fragility curves}

Table 9 summarizes a comparison of the inundation depth at each damage probability between the developed fragility curves and the existing fragility curves proposed by previous studies. The results from Banda Aceh, Okushiri, Phang Nga, and Phuket show the same trend in damage probabilities. These were developed from a combination of various building materials. A damage probability of $25 \%$ occurred at around $2-3 \mathrm{~m}$, of $50 \%$ at $3-4 \mathrm{~m}$, of $75 \%$ at $4-4.5 \mathrm{~m}$, and $100 \%$ at a depth exceeding $6 \mathrm{~m}$. Fragility curves developed using the reinforced concrete building survey data in six provinces in Thailand show higher values at the same damage probability. Moreover, these tsunami fragilities conform well with Matsutomi's criteria for structural destruction (Matsutomi and Harada, 2010) which were based on survey data (Table 10). In brief, fragility curves using visual inspection from high-resolution satellite images for each location show no considerable differences, and only some small differences at each level. Actually, it should be realised that tsunami characteristics and building materials used in Asian countries might differ. Therefore, the fragility curves could be different for tsunami events on other continents. Users verifying the potential building damage against tsunamis should select and apply these fragility curves with care for the reasons explained above for building materials, location, local effect, and limitations of numerical simulations.

\subsection{Tsunami fragility curves for damaged buildings in Thailand and their differences}

According to the population and housing census data from the National Statistical Office of Thailand (2008), construction materials of buildings in the two study areas differ 
Table 10. Matsutomi's criteria for structural destruction.

\begin{tabular}{|c|c|c|c|c|c|c|}
\hline \multirow{2}{*}{ Building materials } & \multicolumn{3}{|c|}{ Medium } & \multicolumn{3}{|c|}{ Severe } \\
\hline & $\begin{array}{l}\text { Inundation } \\
\text { depth } \\
\text { (m) }\end{array}$ & $\begin{array}{l}\text { Current } \\
\text { velocity } \\
\left(\mathrm{m} \mathrm{s}^{-1}\right)\end{array}$ & $\begin{array}{l}\text { Hydrodynamic } \\
\text { force } \\
\left(\mathrm{kN} \mathrm{m}^{-1}\right)\end{array}$ & $\begin{array}{l}\text { Inundation } \\
\text { depth } \\
\text { (m) }\end{array}$ & $\begin{array}{l}\text { Current } \\
\text { velocity } \\
\left(\mathrm{m} \mathrm{s}^{-1}\right)\end{array}$ & $\begin{array}{l}\text { Hydrodynamic } \\
\text { force } \\
\left(\mathrm{kN} \mathrm{m}^{-1}\right)\end{array}$ \\
\hline Reinforced concrete & - & - & - & $>8.0$ & $>5.8$ & $>155-281$ \\
\hline Stone, brick or concrete block & 3.0 & 3.6 & $21.8-39.6$ & 7.0 & 5.5 & $118-215$ \\
\hline Wood & 1.5 & 2.5 & $5.4-9.9$ & 2.0 & 2.9 & $9.7-17.6$ \\
\hline Damage level & \multicolumn{3}{|c|}{$\begin{array}{l}\text { Most columns were remaining but partial damage oc- } \\
\text { curred at wall }\end{array}$} & \multicolumn{3}{|c|}{$\begin{array}{l}\text { Total damage at wall with breakage or collapse found } \\
\text { in most columns }\end{array}$} \\
\hline
\end{tabular}

Table 11. Private households by construction materials of dwelling unit and area (in 2000)*.

\begin{tabular}{lcccc}
\hline Construction materials of dwelling unit and area & \multicolumn{2}{c}{ Phang Nga (Non-municipal area) } & Phuket (Municipal area) \\
\hline Total (household/percent) & 50975 & 100.0 & 26238 & 100.0 \\
Cement or brick & 17146 & 33.6 & 11586 & 44.2 \\
Wood and cement or brick & 6490 & 12.7 & 3860 & 14.7 \\
Mainly permanent materials & 21042 & 41.3 & 9191 & 35.0 \\
Non-permanent materials & 5323 & 10.4 & 1016 & 3.9 \\
Reused materials & 659 & 1.3 & 456 & 1.7 \\
Unknown & 314 & 0.6 & 131 & 0.5 \\
\hline
\end{tabular}

* Excluding private households of which residences are rooms, office rooms, and mobile residences

Table 12. Parameters for tsunami fragility curves for structural destruction of reinforced concrete (RC) structures as a function of the inundation depth.

\begin{tabular}{lccccc}
\hline$X$ for fragility function $P(x)$ & $\mu$ & $\sigma$ & $\mu^{\prime}$ & $\sigma^{\prime}$ & $R^{2}$ \\
\hline Damage level 1 (RC) & - & - & -1.037 & 1.0455 & 0.83 \\
Damage level 2 (RC) & - & - & 0.615 & 1.241 & 0.71 \\
Damage level 3 (RC) & - & - & 1.686 & 0.660 & 0.77 \\
\hline
\end{tabular}

Table 13. Parameters for tsunami fragility curves for structural destruction of the mixed type of building materials as a function of the inundation depth.

\begin{tabular}{lcccccc}
\hline$X$ for fragility function $P(x)$ & $\mu$ & $\sigma$ & $\mu^{\prime}$ & $\sigma^{\prime}$ & $R^{2}$ \\
\hline Mix type & - & - & 0.747 & 0.984 & 0.88 \\
Damage level 3 (RC) & - & - & 1.686 & 0.660 & 0.77 \\
Wood & - & - & 0.241 & 0.697 & 0.83 \\
\hline
\end{tabular}

greatly (Table 11). The tsunami-affected area in Khao Lak, Phang Nga, was large and located in non-municipal areas. On the contrary, Kamala and Patong are densely populated with commercial and tourist facilities, and are located in mu- nicipal areas. The percentage of non-permanent materials and reused materials for building construction in Phang Nga is $11.7 \%$, but only $5.6 \%$ in Phuket. On the other hand, $44.2 \%$ of buildings in Phuket were constructed using concrete or brick, while the percentage of this type of housing in Phang Nga was $33.6 \%$. For these reasons, buildings in Phuket were apparently stronger than those in Phang Nga.

The differences in damage characteristics of buildings in Phang Nga and Phuket due to the construction materials are represented by the developed fragility curves in this study. Although the inundation depth of $6 \mathrm{~m}$ engenders $100 \%$ damage probability in both locations, a lower inundation depth of $2 \mathrm{~m}$ is more fragile in Phang Nga: the damage probability would be $25 \%$ in Phuket but would be as high as $35 \%$ in Phang Nga. The current information on damaged buildings in Phuket is not sufficient to plot the damage probability up to $100 \%$ for both the current velocity and hydrodynamic force. Estimation of the damage probability is obtainable from a projection based on available data. Because the visual damage interpretation uses images taken before and after the tsunami using house roofs for judgment, the structural damage definitely resulted mostly from the tsunami inundation levels. In addition, the impact of floating debris is complex and cannot be included in the numerical model. Some buildings might have been heavily damaged through attack by the floating debris even though the inundation depth and current velocity were small. In other words, the calculated 


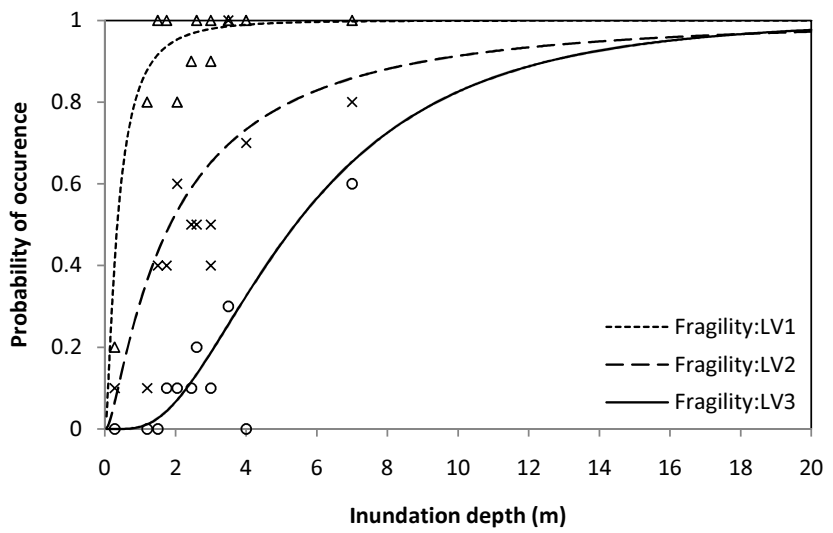

Fig. 15. Tsunami fragility curves for structural destruction of reinforced concrete structure as a function of the inundation depth.

hydrodynamic force shown in the tsunami fragility curves might be overestimated because buildings that were attacked by the floating debris required smaller hydrodynamic force to be damaged than buildings only inundated by the tsunami at the same damage level. Koshimura et al. (2009c) recommended applying the fragility function with regard to the inundation depth because, in addition to the approximation of the model itself, the estimation of current velocity is affected significantly by the grid resolution, the accuracy of topography data and the resistance law.

\subsection{Tsunami fragility curves for different building materials}

The surveyed tsunami runup database in Thailand is provided by Foytong (2007) and Chulalongkorn University team (CUEVR, 2009). In fact, Foytong (2007) had already proposed the tsunami fragility curves for three damage levels of RC building. They used the building data at steps of $0.5 \mathrm{~m}$ to calculate the damage probability curve (for each damage level). However, their database does not cover the whole range of inundation depths for fragility curve development. For example, there is no building damage at level 3 between $3.5 \mathrm{~m}$ and $6.0 \mathrm{~m}$ in this database, which led the damage probability for the five points in this interval to zero in their developed curve. In other words, the probability of damage level 3 became zero during the inundation depth of 3.5-6.0 $\mathrm{m}$ even though the probability of less than $3.5 \mathrm{~m}$ is 0.3 and higher than $6.0 \mathrm{~m}$ is one. To avoid the discontinuity of the data, this study calculated the damage probability at the same number of building samples, every 100 buildings in Phang Nga (total 3007 buildings) and every 50 buildings in Phuket (total 1589 buildings) as explained in Sect. 5.2. Tsunami features such as inundation depth are then obtained by taking the median of each sample group of 100 or 50 buildings. Using the same original building damage data, but a different approach, the tsunami fragility curves for three damage levels of reinforced

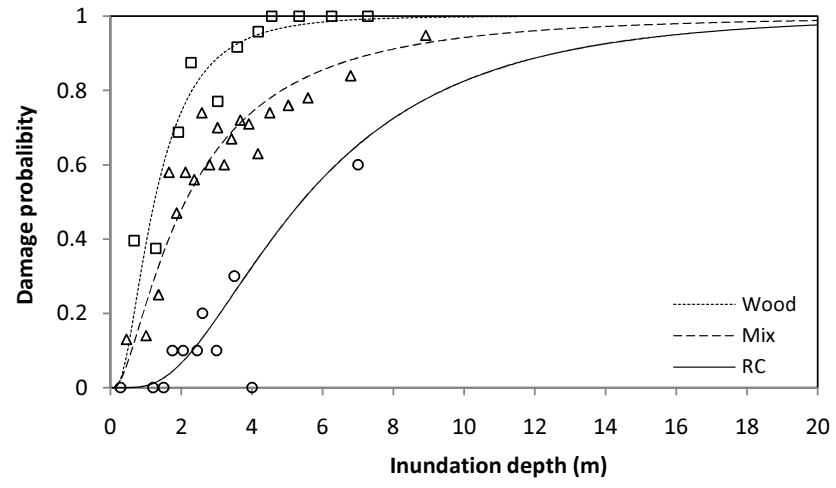

Fig. 16. Tsunami fragility curves for structural destruction of the reinforced concrete and mix type structure as a function of the inundation depth.

concrete (RC) building are then re-plotted as presented in Fig. 15. The related parameters for fragility curves are presented in Table 12. Damage levels of 1, 2, and 3 respectively represent the structural damage in secondary members (roof and wall) only, damage in primary members (beam, column and footing), and collapse. For example, at $3 \mathrm{~m}$ inundation depth, the damage probability of damage levels 1,2 , and 3 respectively becomes $1.0,0.7$, and 0.2 . On the other hand, the raw data of structural damage in Phang Nga and Phuket were then combined and used to develop the fragility curves as a function of inundation depth for the mixed type of building materials in Thailand (Fig. 16). In Fig. 16, the fragility curve for wooden house in Japan (Koshimura et al., 2009a) is also included to show the structural performance of different building materials. Parameters for the fragility curve of the mixed type of building materials is presented in Table 13 with a comparison of the damage level 3 of RC building and wooden house. The developed fragility curves in Fig. 16 show good agreement with surveyed data from Matsutomi and Harada (2010) because the moderate and severe damage of wooden buildings starts respectively from 1.5 and $2 \mathrm{~m}$. It can be presumed that structural damage at the inundation depth of less than $2 \mathrm{~m}$ is considered for wooden buildings. Structural damage of brick or concrete block buildings then starts at $2 \mathrm{~m}$ and almost destroys the structure. Then, the inundation depth reaches $7-8 \mathrm{~m}$, as seen from the different area of the solid line and dotted line. Finally, the structural damage of RC buildings is apparent from Fig. 16 when the inundation depth is greater than about $10-12 \mathrm{~m}$.

\subsection{Conclusions}

The 2004 Indian Ocean tsunami was simulated to obtain tsunami features through high resolution bathymetry data and tsunami inundation modeling. The simulated tsunami propagation was validated against waveforms recorded by tide gauges surrounding Thailand. The simulation illustrated the effect of detailed bathymetry data as an improvement of 
the simulated tsunami waveform at the tide gauge stations. The tsunami inundation model results were validated and found to be consistent with the survey data of water levels, inundation depths, and current velocity from the survivors' videos. The results presented demonstrate good performance of the simulated model in terms of both RMSE and Aida $K$ and $\kappa$ values. High-resolution satellite images (IKONOS) obtained before and after the tsunami event were used via GIS analysis along with the visual inspection of damaged buildings based on the remaining roofs. Fragility curves were developed from the tsunami features computed from the model and from damaged building data. The fragility curves of buildings in Phang Nga and Phuket proposed by this study show similar performance of buildings compared to those of Indonesia and Japan. The buildings started to collapse at 2-3 $\mathrm{m}$ inundation depth and collapsed entirely when the depth exceeded $6 \mathrm{~m}$. The fragility curves proposed using the surveyed data show higher performance because they were developed only from the reinforced-concrete building data. Thailand is the first country in which tsunami fragility curves were developed for constructed building material of different types by separating the RC buildings (direct survey data) from mixed type buildings and wooden houses (satellite image inspection). The curves developed reflected the structural performance, since RC buildings resulted in having the lowest damage probability followed by mixed type and wood. The proposed fragility curves are useful for producing loss estimations for potential tsunamis in Thailand. Also, they are applicable to various countries. However, these fragility curves should be applied with care because they depend on the characteristics of the tsunamis and of building materials that might be different in different countries.

Acknowledgements. We express our deep appreciation to the Ministry of Education, Culture, Sports, Science and Technology (MEXT), Industrial Technology Research Grant Program in 2008 (Project ID: 08E52010a) from New Energy and Industrial Technology Development Organization (NEDO) and the Willis Research Network (WRN) for the financial support of this study.

Edited by: S. Tinti

Reviewed by: S. Scheer and M. Papathoma-Koehle

\section{References}

Aburaya, T. and Imamura, F.: The proposal of a tsunami run-up simulation using combined equivalent roughness, Annual Journal of Coastal Engineering, Japan Society of Civil Engineers, 49, 276-280, 2002 (in Japanese).

Aida, I.: Reliability of a tsunami source model derived from fault parameters, J. Phys. Earth, 26, 57-73, 1978.

Asian Disaster Preparedness Center (ADPC): The economic impact of the 26 December 2004 earthquake \& Indian Ocean tsunami in Thailand, available at: http://www.adpc.net/maininforesource/ dms/Thailand_AssessmentReport.pdf, access: 21 July 2007.
Center of Excellence in Earthquake Engineering and Vibration (CU-EVR), Department of Civil Engineering, Chulalongkorn University, Bangkok, Thailand: Database of Structural Damage due to the Asian Tsunami in Thailand, http://evr.eng.chula.ac.th/ earthquake/DamageSurvey/view.asp, access: 27 March 2009.

Department of Disaster Prevention and Mitigation (DDPM), Ministry of Interior, Thailand: Tsunami damage report, http://61.19. 54.131/tsunami/index.php?pack=overall, access: 6 August 2007 (in Thai).

Federal Emergency Management Agency (FEMA): Coastal construction manual, Third Edition (FEMA 55), 296 pp., 2003.

Foytong, P.: Fragility of buildings damaged in the 26 December 2004 tsunami, Master thesis, Graduate School of Engineering, Chulalongkorn University, Bangkok, Thailand, 2007 (in Thai).

Foytong, P. and Ruangrassamee, A.: Fragility curves of reinforcedconcrete buildings damaged by a tsunami for tsunami risk analysis, The Twentieth KKCNN Symposium on Civil Engineering, Jeju, Korea, 4-5 October 2007, S8-47, 2007.

Gokon, H., Koshimura, S., and Matsuoka, M.: in: Proceedings of the 8th International Workshop on Remote Sensing for Post Disaster Response, Tokyo Institute of Technology, Tokyo, Japan, 30 September-1 October 2010, (CD-ROM), 2010.

Hong, S. J.: Study on the Two and Three Dimensional Numerical Analysis of Tsunamis near a coastal Area, PhD thesis, Graduate School of Engineering, Tohoku University, Sendai, Japan, 2004.

Imamura, F.: Review of tsunami simulation with a finite difference method, Long-Wave Runup Models, World Scientific, 25-42, 1995.

Japan Society of Civil Engineers (JSCE): Tsunami assessment method for nuclear power plants in Japan, available at: http://www.jsce.or.jp/committee/ceofnp/Tsunami/eng/JSCE_ Tsunami_060519.pdf, 2002.

Koshimura, S. and Kayaba, S.: Tsunami damage detection using high- resolution optical satellite imagery, in: Proceedings of the 6th International Workshop on Remote Sensing for Post Disaster Response, University of Pavia, Italy, 11-12 September 2008 (CD-ROM), 2008.

Koshimura, S. and Yanagisawa, H.: Developing fragility curves for tsunami damage estimation using the numerical model and satellite imagery, in: Proceedings of the 5th International Workshop on Remote Sensing for Disaster Response, George Washington University, Washington, United States, 10-12 September 2007 (CD-ROM), 2007.

Koshimura, S., Matsuoka, M., and Kayaba, S.: Tsunami hazard and structural damage inferred from the numerical model, aerial photos and SAR imageries, in: Proceedings of the 7th International Workshop on Remote Sensing for Post Disaster Response, University of Texas, Texas, United States, 22-23 October 2009 (CD-ROM), 2009a.

Koshimura, S., Namegaya, Y., and Yanagisawa, H.: Tsunami Fragility - A new measure to assess tsunami damage, Journal of Disaster Research, 4, 479-488, $2009 \mathrm{~b}$.

Koshimura, S., Oie, T., Yanagisawa, H., and Imamura, F.: Developing fragility curves for tsunami damage estimation using numerical model and post-tsunami data from Banda Aceh, Indonesia, Coast. Eng. J., 51, 243-273, 2009c.

Land Development Department: Land use in Phang Nga and Phuket province during 2000-2002, http://www.ldd.go.th, 2008.

Matsutomi, H. and Harada, K.: Tsunami-trace distribution around 
building and its practical use, in: Proceedings of the 3rd International tsunami field symposium, Sendai, Japan, 10-11 April 2010, session 3-2, 2010.

National Statistical Office Thailand: Population and housing census, http://web.nso.go.th/pop2000/pop_e2000.htm, access: 8 February 2008.

Okada, Y.: Surface deformation due to shear and tensile faults in a half space, Bull. Seism. Soc. Am., 75, 1135-1154, 1985.

Research Group on the December 26, 2004 Earthquake Tsunami Disaster of Indian Ocean: http://www.drs.dpri.kyoto-u.ac.jp/ sumatra/index-e.html, access: 27 March 2009.
Ruangrassamee, A., Yanagisawa, H., Foytong, P., Lukkunaprasit, P., Koshimura, S., and Imamura, F.: Investigation of TsunamiInduced Damage and Fragility of Buildings in Thailand after the December 2004 Indian Ocean Tsunami, Earthq. Spectra, 22, 377-401, 2006.

Suppasri, A., Imamura, F., and Koshimura, S.: Comparison among the proposed source models for the 2004 Indian Ocean tsunami, in: Proceedings of the 2008 Western Pacific Geophysics Meeting, Cairns, Australia, 29 July-1 August 2008, U35B, 2008.

Suppasri, A., Imamura, F., and Koshimura, S.: Effect of rupture velocity of fault motion, ocean current and initial sea level on the transoceanic propagation of tsunami, Coast. Eng. J., 52(2), 107-132, doi:10.1142/S0578563410002142, 2010. 